\title{
How health system factors influence referral decisions in patients that may have cancer: European symposium report
}

\author{
Michael Harris ${ }^{1, *}$, Peter Frey², Magdalena Esteva ${ }^{3}$, Svjetlana Gašparović-Babić ${ }^{4}$, Mercè Marzo-Castillejo ${ }^{5}$, Davorina Petek 6 , \\ Marija Petek Ster ${ }^{6}$ and Hans Thulesius ${ }^{7}$

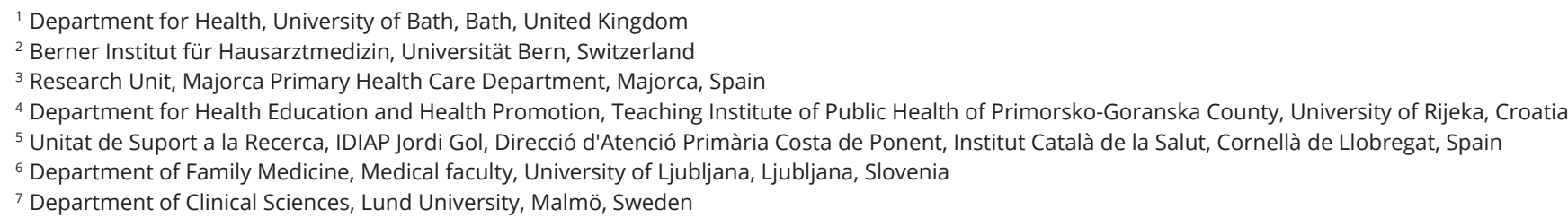

\section{Abstract}

Objective: To identify the system and other non-clinical factors that may influence a General Practitioners' decision on whether to refer a patient who may have cancer. Study design: Expert group discussion and consensus formation. Methods: A group of eight General Practitioner (GP) researchers from Croatia, England, Slovenia, Spain, Sweden and Switzerland used brainstorming to identify the nonclinical factors that could affect GPs' decision-making when faced with patients that might have cancer. The group refined and came to a consensus on these factors. Results: Many non-clinical factors are likely to have a significant impact on referral decisions. These include levels of gatekeeping responsibility, funding systems, access to special investigations, fear of litigation, and relationships with specialist colleagues. Conclusions: Many patients with cancer present without red-flag symptoms, but nevertheless still cause a feeling of concern in their GPs. How a health system is organised is likely to influence on how GPs act on those concerns.

Keywords: health care systems; primary health care; cancer; decision making; early detection of cancer

\section{Introduction}

There is wide variation in the cancer survival rates across Europe [1], and this leads to substantial excess mortality. For example, in Great Britain over 6,000 deaths a year that occurred within 5 years of diagnosis would have been avoided if survival in Britain had matched the mean for Europe $[2,3]$; this represents $6-7 \%$ of its cancer-related mortality.

The variation in 1-year survival rates is even higher. An analysis of EUROCARE-4 [4] results by 1-year survival [1] shows a group of countries (including Switzerland and Sweden) with consistently high survival estimates and another group of countries (including England, Slovenia and Croatia) with lower estimates. Spain lies near the middle of the table. Poor 1-year survival rates are generally taken to be an indicator of more advanced disease at diagnosis [3]. For those patients that survive at least a year after their initial cancer diagnosis, there is less national variation. While recent overall cancer survival trends show improvement [5], there is little narrowing in the differences between countries [6].

International variations in cancer outcomes are related to differences in stage at diagnosis, and this may be due to differences in diagnostic delay and awareness of symptoms $[7,8]$. However, the challenge of where and how to achieve more timely diagnosis is a considerable one [9]. A General Practitioner (GP) will see only a handful of new cancers in any one year. GPs may go many years, or indeed a lifetime, without seeing certain rare cancers. In addition, most patients present with evolving and undifferentiated symptoms that are more likely to be interpreted as something other than cancer.

Various factors can trigger GPs to come to think of cancer in a clinical encounter [10]. Awareness of a risk of cancer can arise from: practising basic knowledge, for instance familiarity with "red-flag" symptoms; interpersonal

*Corresponding author: Michael Harris, Department for Health, University of Bath, Claverton Down Road, Bath BA2 7AY, United Kingdom. Tel.: +44 1761 241366; Email: michaelharris681@btinternet.com

Received 06 September 2015 Revised 25 November 2015 Accepted 4 December 2015 Published 11 December 2015

Citation: Harris M, Frey $P$, Esteva M, Gašparović-Babić S, Marzo-Castillejo M, Petek D, Petek Ster M, Thulesius $\mathrm{H}$. How health system factors influence referral decisions in patients that may have cancer: European symposium report. J Cancer Res Ther. 2016; 4(1):7-10. DOI:10.14312/2052-4994.2016-2

Copyright: (c) 2016 Harris M, et al. Published by NobleResearch Publishers. This is an open-access article distributed under the terms of the Creative Commons Attribution License, which permits unrestricted use, distribution and reproduction in any medium, provided the original author and source are credited. 
awareness, for example being alert to patients' verbal cues; intuitive knowing, e.g. a tacit feeling of alarm; fear of cancer, which can affect the thoughts of both doctor and patient. However, there is also evidence that system factors have an effect on early diagnosis of cancer. Healthcare systems with a gatekeeper system have a significantly lower 1-year relative cancer survival than systems without such gatekeeper functions [11]. It may also be that the way in which different healthcare systems support primary care in cancer diagnosis by quick and easy access to investigations is a factor in delayed cancer diagnosis [12].

There has been a call for better understanding of interactions between single health system factors and professional behaviour so that outcomes can be improved [13]. However, there has been little research to explain in which way different national systems influence a GP's referral decisions, and how these may result in such a variable survival rate [9].

The aim of the symposium was to identify the system and other non-clinical factors that may influence a GP's decision on whether or not to refer a patient who may have cancer. The consensus findings are presented in this paper.

\section{Methods}

Eight GP researchers from six countries were invited to take part in a symposium designed to investigate how primary care factors influence the speed of cancer diagnosis. There was purposeful selection of delegates from the Örenäs Research Group (a European primary care research collaborative that investigates the factors influencing the speed of cancer diagnosis in primary care) to represent northern, southern, central and eastern European countries. The symposium took place in Barcelona during the 2014 European General Practice Research Network (EGPRN) Congress. Participant characteristics are summarised in Table 1.

Table 1 Characteristics of participating GPs.

\begin{tabular}{lllll}
\hline $\begin{array}{l}\text { Country of } \\
\text { practice }\end{array}$ & \multicolumn{1}{c}{$\begin{array}{c}\text { Region of } \\
\text { practice }\end{array}$} & Gender & $\begin{array}{c}\text { GP } \\
\text { expe- } \\
\text { rience } \\
\text { (years) }\end{array}$ & Practice setting \\
\hline Croatia & Rijeka & Female & 10 & Urban \\
England & Somerset & Male & 27 & Small town/rural \\
Slovenia & Ljubljana & Female & 25 & Urban \\
Slovenia & Trebnje & Female & 18 & Small town \\
Spain* & Barcelona & Female & - & - \\
Spain* & Mallorca & Female & - & - \\
Sweden & $\begin{array}{l}\text { Kronoberg } \\
\text { County }\end{array}$ & Male & 20 & Medium-sized city \\
Switzerland* & Kanton Bern & Male & 15 & Urban and suburban \\
\hline
\end{tabular}

*Medically qualified GP researchers with no current direct patient contact.

$\mathrm{MH}$ facilitated the two half-days of the symposium. PF began session one with a presentation summarising the existing evidence on 1-year cancer survival rates and the potential role of system factors. Each participant then gave a short presentation of the referral roles of GPs in their health systems.
The group was given the task of identifying the system and other non-clinical factors that could affect a GP's decision-making when faced with a patient that might have cancer. For this phase of creative problem-solving, a brainstorming technique was used. This method followed Osborn's guidelines [14]: criticism of ideas generated was not allowed; "freewheeling" was welcomed; quantity of ideas was encouraged; combination and improvement were sought. $\mathrm{MH}$ had a brief schedule of topics, not issued to the participants, which he used to ensure that the ideas generated touched on all major areas. In the second session, the group discussed, refined, grouped and came to a consensus on the previous day's list of factors. Participants captured the ideas on flip-chart pads; during the symposium $\mathrm{MH}$ also kept notes. These written records were used to produce a list of the factors that had been identified.

After the meeting, the list of factors was circulated to participants for validation and comment. Participants also gave copies to their local GP colleagues for comment. On the third iteration of this process, no significant changes were requested.

\section{Results}

The gatekeeping roles of GPS

The six countries vary in the extent to which their GPs are gatekeepers. GPs in Sweden have no gatekeeping role, while in Switzerland a third of patients choose a health insurance model that uses GPs as gatekeepers. Croatia and Slovenia require their GPs to be gatekeepers within their public health systems, but private patients in those countries can see specialists without a GP referral. In Spain and the United Kingdom (UK), GPs have a gatekeeping role for all patients (Table 2). Whereas in the UK all GPs routinely see children and patients with gynaecological symptoms, in the other five countries those patients usually present to paediatricians (except in Sweden) and gynaecologists instead.

\section{Varying systems for funding medical care}

How referrals are financed has a considerable effect on referral decisions. Medical systems where referral costs are usually met by insurance companies, so do not come out of hospital or primary care budgets (Croatia, Slovenia, Sweden, Switzerland), are likely to have no inhibitory effect on referrals. To some extent that is also the case where GPs and specialists share a budget (for instance in Swiss managed care systems), so who organises any necessary investigations is not important. In two of the participants' health systems, GPs who are considered to have "overreferred" may find their own income affected (Croatia, Spain). Having a budget or quota for specialist referrals or diagnostic tests tends to reduce referrals (Croatia and, for some tests, Slovenia and Spain). Other health systems explicitly put pressure on GPs to reduce referral rates (Croatia, Slovenia, Spain, UK).

\section{Referral systems and waiting times}

Whereas some health systems encourage GPs to refer any patients with possible cancer early, even if there is a low risk of cancer (Denmark, Sweden), in others the 
Table 2 Gatekeeping characteristics of delegates' countries.

\begin{tabular}{|c|c|c|c|c|c|}
\hline Country & $\begin{array}{l}\text { Are GPs gatekeepers for } \\
\text { patients seen within the } \\
\text { public health system? }\end{array}$ & $\begin{array}{c}\text { Are GPs gatekeepers for patients } \\
\text { who pay for specialist care/are } \\
\text { seen outside the public health } \\
\text { system? }\end{array}$ & $\begin{array}{l}\text { Do GPs see } \\
\text { children? }\end{array}$ & $\begin{array}{l}\text { Do GPs see patients } \\
\text { with gynaecological } \\
\text { problems? }\end{array}$ & Comments \\
\hline Croatia & Yes & No & $\begin{array}{l}\text { Not usually } \\
\text { children aged } \\
\text { below } 7 \text { years }\end{array}$ & No & $\begin{array}{l}10 \% \text { self-refer and pay for } \\
\text { specialist consultations Patients } \\
\text { can self-refer for ultrasound and } \\
\text { some other tests if they pay }\end{array}$ \\
\hline England & Yes & Yes & Yes & Yes & \\
\hline Slovenia & Yes & No & Not usually & No & $\begin{array}{l}10 \% \text { self-refer and pay for } \\
\text { specialist consultations }\end{array}$ \\
\hline Spain & Yes & No & $\begin{array}{l}\text { Not up to age } \\
13\end{array}$ & Not usually & $\begin{array}{l}25-30 \% \text { of patients have private } \\
\text { health insurance }\end{array}$ \\
\hline Sweden & Partly & No & Yes & Not usually & $\begin{array}{l}\text { Patients can self-refer to breast } \\
\text { clinics }\end{array}$ \\
\hline Switzerland & \multicolumn{2}{|c|}{$\begin{array}{l}\text { About 33\% of patients opt for a health insurance model that } \\
\text { uses GPs as gatekeepers }\end{array}$} & Not usually & Not usually & $\begin{array}{l}\text { Some patients are more likely to } \\
\text { self-refer to specialists }\end{array}$ \\
\hline
\end{tabular}

focus is perceived to be on how to save costs by reducing the number of referrals (Croatia, Slovenia, UK). Complex referral processes may also be a factor in deterring referrals (Slovenia, Spain, UK).

Waiting lists for investigations or specialist appointments also affect GP decision-making. Access to a fast-track specialist appointment system for patients with suspected cancer can be used to encourage referrals (Croatia, Slovenia, Spain, UK), while in some of these jurisdictions GPs as a whole have been criticised for purportedly overusing that system, and asked to use it less (Croatia, Slovenia, UK). Long waiting times may result in early referrals, where the GP wishes to get patients into the "queue" quickly. Conversely, long waits may discourage referral until the patient has clear red-flag symptoms or signs, or positive investigation results.

\section{Ease of access to investigations}

In some jurisdictions (Spain, Switzerland, Germany) many GPs can perform in-house specialist investigations themselves (for instance diagnostic ultrasound), and in some cases they are paid for providing those facilities (Switzerland, Germany). This may lower their threshold for arranging such investigations. Other medical systems only have those investigations available to GPs outside their practices. There is variation in how much direct access GPS have to such investigations, with some only being available via specialist referral.

\section{Relationship with specialist colleagues}

The relationship with specialist colleagues is another key factor. Whereas in some health systems specialists are seen to welcome referrals (Switzerland, and to some extent in Sweden), in others they are perceived as discouraging them (Croatia, Slovenia, Spain, UK). The ease of being able to telephone or email a specialist for informal discussion and advice facilitates the care of patients who could have cancer (Sweden, Switzerland, and to some extent in Spain), as is the ability to refer to a specialist that the GP knows personally (Sweden, Switzerland). Having a system that prevents the GP from referring to a named specialist may have an inhibiting effect on referrals (Croatia, Slovenia, Spain, UK).

\section{Fear of litigation or complaint}

Fear of litigation, or complaint over a failure to refer, is a significant factor in many countries (Croatia, Slovenia, Spain, Switzerland, UK). In addition, some GPS may be influenced in their decision-making by previous experience of criticism from patients or colleagues when a serious diagnosis was delayed due to a late referral. The opposite experience is also possible, with criticism from patients or colleagues who think that the GP should have managed a presenting problem without referral (UK).

\section{Effect of intensity of workload}

A high workload may make GPs more likely to refer, in an attempt to reduce follow-up appointments (Croatia, Slovenia, Spain, UK). However, if there is an expectation that the GP will write a detailed, comprehensive referral letter, the time taken to do that may discourage the GP from making a referral at that appointment (UK). In Sweden, where a typical GP appointment is 30 minutes, there is more time for patients to mention symptoms that concern them, and more time for the GP to consider whether investigation or referral is needed.

\section{Clinical guidelines can affect referral decisions}

Clinical guidelines can facilitate a GP's decision to refer, by giving advice on which patients need referral because of a risk of cancer. However, some delegates reported referral guidelines that mainly gave advice on how to avoid inappropriate referrals (Croatia, Slovenia, Spain, UK).

\section{Discussion}

The readiness of GPs to act consists of personal attributes (e.g. knowledge and attitudes about cancer, as well as perceptions of the role of GPs) and system factors [15]. This symposium identified many system and other non-clinical factors that are likely to have a significant impact on referral decisions. These include levels of gatekeeping responsibility, funding systems, access to special investigations, fear of litigation, and relationships with specialist colleagues. A recent narrative review was unable to establish a causal correlation between healthcare system characteristics and cancer outcomes [13]. However, the authors conceded that some system factors could have an influence on patient and professional behaviour, and consequently contribute 
to differences in cancer outcomes. There is evidence that, even when high level features suggest similar healthcare systems, there can be considerable variation in the way that healthcare is delivered [16].

The symposium's findings are consistent with studies which show that waiting times for tests and lack of referral guidelines are among the most important issues related to system delay $[17,18]$. There is a clear difference in decision-making between the systems that have some special investigations done by GPs, and those that only have them as part of secondary care. In the former, doing the investigation is facilitated because it is seen as a quick, easy, and possibly income-generating way of making (or ruling out) a sinister diagnosis.

While there is a link between European health systems where GPs act as gatekeepers and poorer 1-year cancer survival rates [11], this symposium found that the degree of GPs' gatekeeping roles varied considerably between the participants' countries. In addition, it may be that gatekeeping encourages GPs to use other diagnostic strategies, such as the 'test of time' [19], which could contribute to longer diagnostic intervals [13].

The considerable differences in healthcare funding systems were also seen by participants to have a clear impact on the referral decisions, particularly where a referral can affect the GP's own income, budget or referral quota. Some health systems specifically encourage GPs to refer patients who may have cancer, even in the absence of redflag symptoms. Conversely, some implicitly discourage referrals, for example through financial penalties or waiting times.

GP decision-making is affected by how much local specialists welcome, or discourage, referrals. The level of rapport between GPs and those specialists is considered to be an important factor, as well as ease of access to specialists for advice before a referral decision is made.

\section{Strengths and weaknesses of the approach}

This symposium allowed experienced medical practitioners from six European countries to generate hypotheses, by comparing and contrasting their experiences of how their own health systems affect cancer referral decision-making. The countries represented are geographically diverse and show a wide variation in their 1-year cancer survival rates.

The findings draw attention to several factors that could feasibly contribute to key differences in the speed of cancer diagnosis in those countries. The results could inform the design of large-scale comparative European studies of cancer delay, since they highlight many of the variables that such a study must consider if meaningful comparisons are to be made.

However, this was a small piece of qualitative work that drew on the experience of eight GP researchers. The small number of participants involved means that system variations in other countries, or within the delegates' own countries, cannot be accounted for, and this may have limited the breadth of the findings.

\section{Conclusions}

Although many patients with cancer present without redflag symptoms, the GP's experience or "gut feeling" may cause a feeling of concern. How the health system is organised is likely to have a strong influence on how the GP acts on that concern. The multitude of factors affecting decision-making makes it likely that, even in the presence of red-flag symptoms, system factors are highly likely to affect whether or not a GP refers immediately. Reducing the time from presentation to specialist referral or investigation is an important step in improving cancer survival. The findings of the symposium propose important hypotheses on the factors that influence that time, and these warrant further research.

\section{Conflicts of interest}

Authors declare no conflicts of interest.

\section{References}

[1] Møller $H$, Linklater KM, Robinson D. A visual summary of the EUROCARE-4 results: a UK perspective. Br J Cancer. 2009; 101(Suppl 2):S110-114.

[2] Abdel-Rahman M, Stockton D, Rachet B, Hakulinen T, Coleman MP. What if cancer survival in Britain were the same as in Europe: how many deaths are avoidable? Br J Cancer. 2009 101(S2):S115-S124.

[3] Richards MA. The size of the prize for earlier diagnosis of cancer in England. Br J Cancer. 2009; 101(Suppl 2):S125-S129.

[4] Eurocare. Survival of cancer patients in Europe: EUROCARE-4. 2011.

[5] De Angelis R, Sant M, Coleman MP, Francisci S, Baili P, et al. Cancer survival in Europe 1999-2007 by country and age: results of EUROCARE5-a population-based study. Lancet Oncol. 2014; 15(1):23-34.

[6] Coleman MP, Forman D, Bryant H, Butler J, Rachet B, et al. Cancer survival in Australia, Canada, Denmark, Norway, Sweden, and the UK, 1995-2007 (the International Cancer Benchmarking Partnership): an analysis of population-based cancer registry data. Lancet. 2011; 377(9760):127-138.

[7] Walters S, Maringe C, Coleman MP, Peake MD, Butler J, et al. Lung cancer survival and stage at diagnosis in Australia, Canada, Denmark, Norway, Sweden and the UK: a population-based study, 2004-2007. Thorax. 2013; 68(6):551-564.

[8] Maringe C, Walters S, Rachet B, Butler J, Fields T, et al. Stage at diagnosis and colorectal cancer survival in six high-income countries: $A$ population-based study of patients diagnosed during 2000-2007. Acta Oncol. 2013; 52(5):919-932.

[9] Foot C, Harrison T. How to improve cancer survival: explaining England's relatively poor rates. The King's Fund, London. 2011.

[10] Johansen ML, Holtedahl KA, Rudebeck CE. How does the thought of cancer arise in a general practice consultation? Interviews with GPs. Scand J Prim Health Care. 2012; 30(3):135-140.

[11] Vedsted P, Oleson F. Are the serious problems in cancer survival partly rooted in gatekeeper principles? An ecologic study. Br J Gen Pract. 2011; 61(589):512-513.

[12] Rubin G, Vedsted P, Emery J. Improving cancer outcomes: better access to diagnostics in primary care could be critical. Br J Gen Pract. 2011; 61(586):317-318.

[13] Brown S, Castelli M, Hunter D, Erskine J, Vedsted P, et al. How might healthcare systems influence speed of cancer diagnosis: A narrative review. Soc Sci Med. 2014; 116:56-63.

[14] Osborn AF. Applied imagination: principles and procedures of creative thinking. New York: Charles Schreibner's Sons. 1953.

[15] Rose PW, Rubin G, Perera-Salazar R, Almberg SS, Barisic A, et al. Explaining variation in cancer survival between 11 jurisdictions in the International Cancer Benchmarking Partnership: a primary care vignette survey. BMJ Open. 2015; 5(5):e007212.

[16] Magnussen J, Saltman RB, Vrangbæk K. Nordic health care systems. Recent reforms and current policy challenges. London: Open University Press. 2009.

[17] Bjerager M, Palshof T, Dahl R, Vedsted P, Olesen F. Delay in diagnosis of lung cancer in general practice. Br J Gen Pract. 2006; 56(532):863868.

[18] Davies E, van der Molen B, Cranston A. Using clinical audit, qualitative data from patients and feedback from general practitioners to decrease delay in the referral of suspected colorectal cancer. J Eval Clin Pract. 2007; 13(2):310-317.

[19] Almond SC, Summerton N. Diagnosis in General Practice. Test of time. BMJ. 2009; 338:b1878. 